\title{
Effect of Selected Spark Motor Program on Anxiety of Children with Asperger
}

\author{
Neda Rezvankhah Golsefidi ${ }^{1}$, Seyed Ali Emami Hashemi ${ }^{*}$ \\ 1. Department of Health and Sport Medicine, Faculty of Physical Education and Sport Sciences, University of Tehran, Tehran, Iran. \\ 2. Department of Health and Sport Medicine, Faculty of Physical Education and Sport Sciences, Kharazmi University, Tehran, Iran.
}

Citation: Rezvankhah Golsefidi N, Emami Hashemi SA. Effect of selected spark motor program on anxiety of children with Asperger. Physical Therapy. 2015; 5(2):83-88. http://dx.crossref.org/10.15412/J.PTJ.07050203

dol: : https://dx.crossref.org/10.15412/J.PTJ.07050203

Article info:

Received: 06 Mar. 2015

Accepted: 02 Jun. 2015
Keywords:

Autism, Exercise,

Anxiety, Children

\begin{abstract}
A B S T RA C T
Purpose: Autism is a developmental disorder characterized by social and communicative problems as well as movement skills. Anxiety is one of the widespread problems among the people affected by autism. The aim of the present research was to survey the effect of one period of selected spark motor program on the anxiety of children with autism.
\end{abstract}

Methods: Twenty autistic children (Asperger symptom) participated in this study. They were divided into experimental and control groups. Experimental group participated in selected spark motor program for 4 weeks. The anxiety level was measured by using Spence children's anxiety scale questionnaire before and after the exercise program. Data were analyzed by using the dependent and independent $t$ test with SPSS 21 and the $\alpha$ value was considered 0.05 .

Results: The results showed that after the exercise program, the level of obsessive-compulsive disorder $(\mathrm{P}<0.001)$, separation anxiety $(\mathrm{P}<0.001)$, social phobia $(\mathrm{P}<0.001)$, general anxiety $(\mathrm{P}=0.02)$, physical injury fears $(\mathrm{P}=0.01)$, and agoraphobia $(\mathrm{P}=0.01)$ decreased significantly in the experimental group. While the control group showed no significant difference.

Conclusion: Training and exercise not only reduce anxiety in autistic children but also can be used as useful nonpharmaceutical method to reduce anxiety.

\section{Introduction}

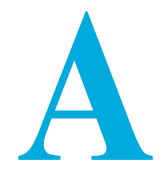

utism is a developmental disorder characterized by social, communication and motor skill problems [1]. The common psychological problem among the autistic people is anxiety. Several studies have shown that autistic children suffer from anxiety. The autistics suffer from anxiety in their personal and social life, and this could be accompanied by serious educational problems, and later in their lives by unemployment and drug abuse. Furthermore, anxiety is the second major concern for parents of autistic children [2]. Prevalence of anxiety in children with autism has confirmed this matter [3]. Chalfant et al. reported the prevalence of anxiety in autistics from $47 \%$ to $84.1 \%$. Evidence suggests that anxiety levels in autistic children are more than children with mental retardation or language disorders.

\footnotetext{
* Corresponding Author:

Seyed Ali Emami Hashemi, PhD Student

Address: Department of Health and Sport Medicine, Faculty of Physical Education and Sport Sciences, Kharazmi University, Tehran, Iran Phone: +98 (913) 2020532

E-mail:aemami@ut.ac.ir
} 
Also, the findings suggest that anxiety in autistic children is more than healthy children [4]. In addition, researchers have reported that anxiety is very common among children with autism, especially Asperger syndrome. In addition, the risk of anxiety is at the highest level in Asperger syndrome as people with this syndrome usually have the highest level of intelligence and the ability to use language and interact with people. Research results show that anxiety increases with increasing severity of autistic disorder. Generally anxiety is accompanied by aggression, oppositional behavior, behavior problems, severe allergies [5], and reduced participation in social activities [2].

Although many studies have shown that autistic children suffer from anxiety, studies on effective treatment for them are not sufficient and the literature review was only about psychological and medical treatment methods for these people. Primary method of treatment is administration of anxiolytic and serotonergic drugs [4]. But there is little evidence regarding the use of medication to treat anxiety.

Generally, psychological treatments focus on techniques of mother-child separation anxiety and body anxiety. However, this method has some limitations such as the small number of subjects and accordingly scarce knowledge in this area. Another approach is cognitive behavior that has positive effects on children with autism. However, the results show that there is a possibility of recurrence of the disease with cognitive behavioral therapy [6]. Limitations of therapies for children with autism show that researchers need to search more effective ways to treat anxiety in people with autism [4].

Physical activity is a possible solution to reduce behavioral problems. Physical inactivity has many disadvantages on health and sense of well-being. It is associated with the development of mental disorders. Some clinical and epidemiological studies have shown that physical inactivity is associated with symptoms of depression and anxiety and have pointed that exercise is an important part of treatment. Promoting sense of well-being improves mental state and it is generally accepted that physical activity has a positive effect on anxiety and mood [7].

Exercise is an effective strategy for the prevention and treatment of anxiety. Also participating in regular physical activities and exercise can reduce anxiety. Physical therapy is more effective compared to stress management, training, stretching yoga, group therapy, meditation, and relaxation. Exercise has a beneficial effect on the mental health of individuals. While this model is not for people with autism. However, published research shows that most children with autism participate less than other children in physical activities.

Despite the low level of participation of autistics in the physical activities, the beneficial impact of exercise on physiological and psychological states of these people has been established. Impact on the quality of life, increased sense of well-being, and improved cognitive aspects and behavioral disorders in people with autism, as well as increased self-confidence are listed in these investigations [8]. The best record was the study of exercise's effects on anxiety in adults with autism.

In this study, researchers divided 18 (2 women, 16 men) adults with autism into 2 groups; control (with Asperger) and exercise therapy. The group with exercise therapy also benefited from relaxation activities. After 8 weeks, researchers have found that anxiety has decreased in experimental group [9]. Also Elliot et al. found that after a period of aerobic exercises, abnormal and stereotyped behaviors reduced in autistic individuals [10]. While Spielberger et al. did not observe anxiety reduction after 1-week training program [11].

Because of contradictory results among researchers, we attempted to investigate the effect of one period of selected spark motor program (including playing) on the anxiety of children with autism. In other words, the researcher seeks whether the physical activity that involves playing in autistic children is effective or not. To answer this question, the effect of a selected spark motor program that originated from spark motor program on sleeping of 6 to 10 year-old children was investigated.

\section{Materials and Methods}

It is a quasi-experimental and applied research study. Twenty 6-10 years old children with Asperger syndrome living in Tehran with the consent of their parents were selected for this study. The children in this age range were selected because they could learn and drill basic motor skills of selected exercises. Inclusion criteria were having anxiety, stable behavior, and no change in body health during the last 3 months. The children that had mental disorder medical status like Cystic Fibrosis, diabetes, Heart disease, asthma and kids with complex neurological disorders for example: phenylketonuria, cerebral palsy, tuberous sclerosis, Unstable seizure disorder were deleted. Research was planned to have pretest and posttest with control group (children with Asperger). Anxiety of children was assessed by Spence children's anxiety scale (SCAS) before starting exercise program. 
Table 1. Characteristics of study subjects.

\begin{tabular}{cccc}
\hline & $\begin{array}{c}\text { Age (year) } \\
\text { Mean } \pm \text { SD }\end{array}$ & $\begin{array}{c}\text { Height (cm) } \\
\text { Mean } \pm S D\end{array}$ & $\begin{array}{c}\text { Weight (kg) } \\
\text { Mean } \pm S D\end{array}$ \\
\hline Experimental group & $2.4 \pm 7.34$ & $4.5 \pm 135$ & $5.7 \pm 30.3$ \\
Control group & $2.1 \pm 7.5$ & $3.9 \pm 134$ & $4.8 \pm 29.7$ \\
\hline
\end{tabular}

PHYSICAL TREA †MENTS

This questionnaire was designed based of parents' reports and the scale evaluates 6 domains of anxiety: 1.generalized anxiety 2.panic/agoraphobia 3.social phobia 4.separation anxiety 5.obsessive compulsive disorder 6.physical injury fears. This scale is designed to be simple and fast for kids to answer it, normally ten minutes is enough to complete it. This measure consists of fortyfore items, of which thirty-eight reflect specific signs of anxiety and six relate to positive, filler items to reduce negative response bias. Of the thirty-eight anxiety items, six items reflect separation anxiety, six social phobia, six obsessive compulsive problems, six panic/three agoraphobia, six generalized anxiety/overanxious symptoms and five items concern fears of physical injury.

Items are haphazardly allocated within the questionnaire. Kids are asked to rate on a fore point scale including never (zero), sometimes (one), often (two), and always (three), the frequency with which they experience each sign. There are no true and false answers. Maximum score was 114 that showed maximum level of anxiety. This test is a general instrument to gain number and Intensity of anxiety signs that can be used for 8-15 children [12].

After completing the questionnaire in pretest, the children were randomly divided into experimental and control groups. Selected exercise program was originated from Spark Motor Program that involves exercising and playing. Two kind of SPARK Physical Education plan are exist: Elementary PE (1.K-2 PE 2. 3-6 PE) and Secondary PE (1. Middle School PE 2. High School PE). Gross motor skills like crawling, balancing and running are expanded during early childhood and are considered as a necessary item of motor development. The major muscle groups are mostly responsible for gross motor movements. Fine motor skills are those attributed to the coordination of minor groups of muscles for example involved in playing piano. Test of Gross Motor Development-edition 2 called TGMD-2 is a norm-reference measurement of gross motor development [22].

The exercise program includes 45 minutes for each session that is divided into 4 parts. The first 15 minutes is allocated to warm up and then playing for 10 minutes that involves motor skill movements, next 10 minutes for manipulation movement skills and finally 10 minutes for cool down. Subjects were homogeneously divided into experimental and control groups. The experimental group did the selected spark motor program 3 times in the week and for a period of 12 sessions. During this period the control group did their routine activity. In the end of the 12th session, the posttest was conducted.

After data collection and confirmation of normal distribution with Kolmogorov-Smirnov test, dependent and independent $t$ test were used for data analyses to compare the mean of different groups on selected period points. The analyses were done by SPSS 21 and $\alpha$ value of 0.05 was considered significant.

\section{Results}

Ten children for experimental group and 10 children for control group participated in this research. The mean values of their height and weight are shown in Table 1.

Result of subscales in pretest and posttest of experimental and control groups are shown in Table 2. Our findings revealed that in post-test the amount of agoraphobia, separation anxiety, social phobia, obsessive compulsive disorder and generalized anxiety decreased significantly but there was no significant different in control group.

\section{Discussion}

The aim of the present research was to survey the effect of one period of selected spark motor program on the anxiety of children that suffer from autism. In the past few decades, the anxiolytic effect of exercise on the people has been investigated. Apparently, exercise has an influence on people's anxiety. Research shows that physical activity and exercise improve the sense of wellbeing. It also promotes psychological mood and generally has an effect on anxiety and temperament [7]. The result of this research indicated that selected spark motor program on autistic children anxiety was effective which is similar to findings of Hillier et al. [9], Petruzzello et al. [13], and Carmelie et al. [14]. 
Table 2. Autistic children's anxiety before and after exercising.

\begin{tabular}{|c|c|c|c|c|c|}
\hline \multicolumn{2}{|c|}{ Variable } & $\begin{array}{l}\text { Before intervention } \\
\qquad M \pm S D\end{array}$ & $\begin{array}{l}\text { After lintervention } \\
\qquad \mathrm{M} \pm \mathrm{SD}\end{array}$ & $\mathbf{t}$ & $\mathbf{P}$ \\
\hline \multirow{2}{*}{ Agoraphobia } & Experimental & $4.12 \pm 5.23$ & $3.14 \pm 3.40$ & 3.38 & 0.00 \\
\hline & Control & $4.45 \pm 5.63$ & $4 \pm 5.01$ & 1.984 & 0.118 \\
\hline \multirow{2}{*}{ Separation anxiety } & Experimental & $4.10 \pm 7.13$ & $3.59 \pm 5.40$ & 3.18 & 0.00 \\
\hline & Control & $3.7 \pm 6.95$ & $4.01 \pm 7.07$ & 5.38 & 0.628 \\
\hline \multirow{2}{*}{ Physical injury fears } & Experimental & $3.27 \pm 4.90$ & $2.15 \pm 2.93$ & $9.86-$ & 0.00 \\
\hline & Control & $3.12 \pm 4.52$ & $2.75 \pm 4.73$ & 1.012 & 0.386 \\
\hline \multirow{2}{*}{ Social phobia } & Experimental & $3.67 \pm 5.09$ & $2.07 \pm 3.40$ & 3.985- & 0.020 \\
\hline & Control & $3.24 \pm 5.35$ & $3.90 \pm 5.9$ & 1.59 & 1.85 \\
\hline \multirow{2}{*}{ Obsessive compulsive disorder } & Experimental & $3.65 \pm 8.45$ & $3.04 \pm 6.15$ & 5.518 & 0.012 \\
\hline & Control & $4.04 \pm 8.02$ & $3.81 \pm 7.67$ & 1.61 & 0.205 \\
\hline \multirow{2}{*}{ Generalized anxiety } & Experimental & $2.80 \pm 5.70$ & $2.50 \pm 3.67$ & 4.562 & 0.01 \\
\hline & Control & $3.4 \pm 5.50$ & $2.90 \pm 5.90$ & 5.96 & 0.688 \\
\hline
\end{tabular}

PHYSICAL TREA TMENTS

In a meta-analysis study, Petruzzello et al. examined the effects of exercise on people with anxiety. Their results showed that exercise reduces anxiety to some extent [13]. Also Hillier et al. research showed that relaxation exercises and techniques reduced anxiety in people with autism. They also reached the conclusion that exercise would reduce cortisol levels [9]. Carraro and Gobbiin in their study showed that a single session of exercise could help reduce anxiety in people with intellectual disabilities [8]. Meanwhile, the results of the present study contradict those of Spielberger et al. They noted that exercise did not reduce the level of anxiety. A possible cause of their failure can be due to using short-term exercises which was limited to one session per week.

Several factors, including psychological and biological ones can affect anxiety. But what makes physical activity so effective in reducing anxiety is still unclear [8]. Some investigations have been clarified anxiolytic effects of exercise on the basis of different mechanisms. Biological and psychological mechanisms are among them. From a biological perspective, we can note the involvement of neurotransmitters in anxiety $[15,16]$, muscle tension, and also reduction of stress hormone levels after sporting activities. Medical report on mental health suggests that biochemical changes in the brain can be affected by anxiety [8].

Studies on the biological effects of exercise on anxiety report several possible findings, including increased central norepinephrine neurotransmitters [17, 18], hypothalamic adrenocortical system changes [16, 18-20], atrial natriuretic peptide secretion increase, also decline in the amino metabolites, synthesis of serotonin, betaendorphin, and cortisol levels [7]. Thus, providing an opportunity to participate in physical activity programs is recommended $[14,15,19,20]$. Regarding the mental aspect of exercise, an increase in the level of activity is associated with positive reinforcement conditions that cause a deviation from the conditions of distress. Exercise provides a basis for increased self-confidence and sense of self-esteem that can reduce anxiety [21]. It also appears that exercise effects persist over time and may reduce the physiological arousal and distress. In the combined exercise intervention e.g., physical fighting, the experience of improving skills and social relationships due to body and muscle relaxation can help reduce anxiety [8]. The findings of this study support the anxiolytic effect of exercise on reducing anxiety and indicate that exercise can be used as a useful and nonpharmacologic instrument for decreasing anxiety. One of the limitations of this study was small sample size. Hence, we suggest the same research be performed on more subjects with different ages. Furthermore, the future studies can be about physiology and biochemical effects of exercise on people with autism. For an accurate study on the mechanism of exercise on anxiety, we suggest psychological assessments and long-term pursuit to elucidate the anxiolytic effects of exercise on these people.

\section{Acknowledgements}

The current research hasn't received any financial support.

\section{Conflict of Interests}

The authors declared no conflict of interests. 


\section{References}

[1] Bass MM, Duchowny CA, Llabre MM. The effect of therapeutic horseback riding on social functioning in children with autism. Journal of Autism and Developmental Disorders. 2009; 39(9):1261-267.

[2] Selles RR, Storch EA. Translation of anxiety treatment to youth with autism spectrum disorders. Journal of Child and Family Studies. 2013; 22(3):405-13.

[3] Kim JA, Szatmari P, Bryson SE, Streiner DL, Wilson FJ. The prevalence of anxiety and mood problems among children with autism and Asperger syndrome. Autism. 2000; $4(2): 117-32$.

[4] Chalfant AM, Rapee R, Carroll L. Treating anxiety disorders in children with high functioning autism spectrum disorders: a controlled trial. Journal of Autism and Developmental Disorders. 2007; 37(10):1842-857.

[5] Mayes SD, Calhoun SL, Murray MJ, Zahid J. Variables associated with anxiety and depression in children with autism. Journal of Developmental and Physical Disabilities. 2011; 23(4):325-37.

[6] Dunn AL, Weintraub P. Exercise in the prevention and treatment of adolescent depression: a promising but little researched intervention. American Journal of Lifestyle Medicine. 2008; 2(6):507-18.

[7] Ströhle A. Physical activity, exercise, depression and anxiety disorders. Journal of Neural Transmission. 2009; 116(6):777-84

[8] Carraro A, Gobbi E. Effects of an exercise programme on anxiety in adults with intellectual disabilities. Research in Developmental Disabilities. 2012; 33(4):1221-226.

[9] Hillier A, Murphy D, Ferrara C. A pilot study: short-term reduction in salivary cortisol following low level physical exercise and relaxation among adolescents and young adults on the Autism spectrum. Stress and Health. 2011; 27(5):395-402.

[10] Elliott RO, Dobbin AR, Rose GD, Soper HV. Vigorous, aerobic exercise versus general motor training activities: Effects on maladaptive and stereotypic behaviors of adults with both autism and mental retardation. Journal of Autism and Developmental Disorders. 1994; 24(5):565-76.

[11] Spielberger CD, Gorsuch RL, Lushene RE, Vagg PR. Statetrait anxiety inventory (STAI). Palo Alto, C.A.: Consulting Psychologists Press; 1970.

[12] Mousavi R, Moradi A, Farzad V, Mahdavi S. Psychometric properties of the Spence children's anxiety scale with an Iranian sample. International Journal of Psychology. 2007; 1(1):17-26.

[13] Petruzzello SJ, Landers DM, Hatfield BD, Kubitz KA, Salazar W. A meta-analysis on the anxiety-reducing effects of acute and chronic exercise. Sports Medicine. 1991; 11(3):143-82.

[14] Carmeli E, Zinger-Vaknin T, Morad M, Merrick J. Can physical training have an effect on well-being in adults with mild intellectual disability? Mechanisms of Ageing and Development. 2005; 126(2):299-304.

[15] Binding L, Randall J. Anxiety as a barrier to student performance. Canadian Nurse. 2004; 100(6):7-15.
[16] Simons AD, Epstein LH, McGowan CR, Kupfer DJ, Robertson RJ. Exercise as a treatment for depression: an update. Clinical Psychology Review. 1985; 5(6):553-68.

[17] Doyne EJ, Ossip-Klein DJ, Bowman ED, Osborn KM, McDougall-Wilson IB, Neimeyer RA. Running versus weight lifting in the treatment of depression. Journal of Consulting and Clinical Psychology. 1987; 55(5):748-54.

[18] Sothmann MS, Ismail A. Factor analytic derivation of the MHPG/NM ratio: implications for studying the link between physical fitness and depression. Biological Psychiatry. 1985; 20(5):580-83.

[19] Droste SK, Gesing A, Ulbricht S, Muiller MB, Linthorst AC, Reul JM. Effects of long-term voluntary exercise on the mouse hypothalamic-pituitary-adrenocortical axis. Endocrinology. 2003; 144(7):3012-023.

[20] Strohle A, Holsboer F. Stress responsive neurohormones in depression and anxiety. Pharmacopsychiatry. 2003; 36(3):207-14.

[21] Ossip-Klein DJ, Doyne EJ, Bowman ED, Osborn KM, Neimeyer RA. Effects of running or weight lifting on selfconcept in clinically depressed women. Journal of Consulting and Clinical Psychology. 1989; 57(1):158-64.

[22] Ulrich DA. Test of gross motor development-2. Austin, T.X.: Prod-Ed Press; 2000. 
